\title{
Team feedback intervention and team learning in virtual teams: A moderated mediation model of team cohesion and personality
}

\author{
Jesús Sánchez Gómez ${ }^{10000-0002-9260-9985]}$, Ana Zornoza Abad ${ }^{1[0000-0002-9407-0821]}$, Virginia \\ Orengo Castellá ${ }^{1[0000-0001-8520-216 X]}$, Vicente Peñarroja Cabañero ${ }^{2[0000-0001-6827-2086]}$ and \\ Petros Chamakiotis $3[0000-0001-7109-310 \mathrm{X}]$ \\ ${ }^{1}$ Universitat de València, Avenida Blasco Ibáñez 21, Valencia 46010, Spain \\ ${ }^{2}$ Universitat Autònoma de Barcelona, Campus de Bellaterra, Barcelona 08193, Spain \\ ${ }^{3}$ University of Sussex, Brighton BN1 9SL, United Kingdom \\ P.Chamakiotis@sussex.ac.uk
}

\begin{abstract}
Scholars and practitioners agree that virtual teams (VTs) have become commonplace in today's digital workplace. Relevant literature argues that learning constitutes a significant contributor to team member satisfaction and performance, and that, at least in face-to-face teams, team cohesion fosters team learning. Given the additional challenges VTs face, e.g. geographical dispersion, which are likely have a negative influence on cohesion, in this paper we shed light on the relationship between team cohesion and team learning. We adopted a quantitative approach and studied 54 VTs in our quest to understand the role of feedback in mediating this relationship and, more specifically, the role of personality traits in moderating the indirect effect of team feedback and guided reflection intervention on TL through team cohesion within the VT context. Our findings highlight the importance of considering aspects related to the team composition when devising intervention strategies for VTs, and provide empirical support for an interactionist model between personality and emergent states such as cohesion. Implications for theory and practice are also discussed.
\end{abstract}

Keywords: virtual teams, team cohesion, team learning, computer-mediated communication.

\section{Introduction}

Today's organizations rely extensively on virtual teams (VTs) supported by rapid technological advancements and globalization [1]. These teams have become an essential mechanism in the creation of valuable knowledge and learning in modern organizations. In addition, learning is an important process that helps teams and organizations to adapt to the ever-changing environment and achieve their goals $[2,3]$. Thus, the present study focuses on learning at the team level, and team learning (TL) 
is conceptualized as a process of adapting to change that leads to enhanced understanding or improved performance in teams [4]. Likewise, it helps team members to build and maintain a mutually shared cognition that increases perceived team performance [5]. Ortega et al. [6] highlighted that TL is a vital aspect in VTs, showing that it fosters satisfaction, team viability, and performance. TL is a social process that emerges through team members' interactions, which are influenced by beliefs about the team's interpersonal context [3]. In this context, the present study focuses on team cohesion, which has been found to foster TL in face-to face teams "by increasing the motivation, trust, and cognitive familiarity for productive inquiry" [7].

VTs have some advantages, like the possibility to overcome geographical, temporal and organizational barriers, which facilitates the inclusion of members with diverse skills and knowledge [8]. However, VTs' characteristics pose several challenges to learning. For example, these teams might experience an increased difficulty to build a shared understanding [9], take longer time to reach an agreement [10], and experience difficulties in information processing [11]. Furthermore, some authors consider that in teams with high virtuality it might be difficult to develop ties between members, which can hinder the development of relational processes, emergent states, and negatively influence performance and collaboration [12]. Consequently, technological mediation has been found to have a negative impact on cohesiveness, affecting interpersonal and normative bonds in VTs [12]. Consequently, some authors point that training interventions may be a viable strategy to overcome these challenges [13]. Following this logic, we developed a team feedback intervention which includes a period of reflection, to examine how to improve team cohesion and learning in virtual teams. In this intervention, after receiving process and results feedback, the teams engaged in a period of joint reflection. Furthermore, taking into consideration that team cohesion emerges from the social interactions between team members, it is necessary to ponder how the composition of the team, concretely deep-level composition characteristics like the personality of the team, can play a relevant role in this relationship [13-15].

In sum, the present study aims to investigate a moderated mediation model in which team personality moderates the indirect effect of team feedback on team learning through team cohesion in virtual teams.

\subsection{Team cohesion and learning in virtual teams.}

Identifying the conditions that promote TL has been a significant area of study during the last decade, emphasizing the importance of several emergent states in the development of TL [4, 5]. Following Van den Bossche et al. [3] team cohesion is a relevant factor for team learning. Previous research has found that cohesive teams tend to display greater team mental model convergence and enhanced collaboration, communication, and trust, creating an environment that facilitates TL [2], [5]. In this study, team cohesion is conceptualized as team members' tendency to stay together because of positive relationships with other members and shared commitment to the team's task $[15,16]$. 
However, despite the importance of team cohesion in facilitating TL, to our knowledge, research about this relationship in VTs is scarce [3]. In general, VTs face challenges that interfere with the creation of a positive social atmosphere and strong relationships among team members [1]. Following the Media Richnness Theory, computer-mediated communication (CMC) is less rich and hinders the development of relationships, group cohesion, and problem solving during the initial stages of the team [17]. In virtual settings, cohesion needs more time to develop [18], and is more difficult due to the lack of information [12]. However, VTs that receive training based on feedback and collective reflection have been found to display greater cohesion and collaborate in a more constructive way [19-21].

\subsection{The effect of a team feedback and reflection-based intervention}

Lacerenza and collaborators [13] stated that organizations can facilitate success in VTs through training, and called for research on training strategies in VT. The present paper proposes a training intervention based on feedback and guided reflection as a strategy to improve a VT's learning and cohesion [20], [22]. Team feedback consists of information provided by an external agent about previous actions, events, processes, and behaviors related to the task and the team's functioning [20]. Previous research suggests that providing feedback to teams has a positive impact on team cohesion [19]. Concretely, teams that receive feedback spend time discussing their reactions to the feedback and how to improve the team's functioning, and they work toward establishing the team's goals [19]. Furthermore, a period of guided collective reflection may help team members to change their teamwork by uncovering ways to improve and clarifying misunderstandings [20], [23].

Following the Social Information Processing theory, Burke and collaborators [17] found that cohesion in computer-mediated communication environments is lower than in face-to-face teams and develops over time. Moreover, they found that, as members share and discuss information and their opinions converge, they experience increased cohesion [17], which can be facilitated by feedback and guided reflection intervention. In this vein, Villado and Arthur [21] conducted a study comparing teams that carried out "After Action Reviews" (AAR) with teams that did not. Their results suggested that setting goals collaboratively, reviewing and discussing strategies and behaviors to improve performance, facilitated the emergence of team cohesion [21]. Furthermore, Gabelica and collaborators [20] pointed out that team feedback followed by guided group reflection helps teams to process the feedback, improving performance and learning in face-to-face teams. Therefore, based on the previous rationale, we propose the first hypothesis:

Hypothesis 1: Team feedback and guided reflection will have a positive indirect effect on TL via team cohesion in VTs. 


\subsection{The role of team personality}

Furthermore, the impact of interventions on team processes and emergent states might be influenced by the team's composition [13], [24]. Some authors highlight that the personality of team members can alter relational patterns during teamwork and the way the team adapts to changes [14]. This can modify the relationship between the team feedback and guided reflection intervention and team cohesion $[25,26]$. However, the interactive effects of more profound team composition characteristics like personality on team processes have seldom been studied in VTs [1], [24], [27]. In the context of the present research, team personality is understood as the average team level of two relevant personality traits [15], [27], [28]. The question addressed in this study is how team personality traits influence the effect of a team feedback and guided reflection intervention on TL, via team cohesion, in VTs.

The present study focuses on two personality traits, openness to experience and agreeableness, which influence the development of team cohesion and TL on highly interactive tasks [29]. First, openness to experience is defined as the tendency to be open-minded, flexible, imaginative, and curious [30]. High openness to experience indicates a tendency to not avoid conflict and to try to solve problems collaboratively by seeking alternative solutions [27]. Furthermore, open individuals are more helpful when interacting in a team context, and they have positive attitudes toward minorities [27]. Therefore, teams with high scores on openness are considered more adaptable and open to experiencing new things and collaborating [31]. Openness also facilitates team adaptation and the generation of alternatives and testing of new ideas [14]. These characteristics might help to develop cohesion in teams that receive and review feedback collectively and collaboratively, whereas their absence could hinder this process. Second, agreeableness is defined as a tendency to be good-natured, friendly, cooperative, modest, and tolerant [30]. Individuals with high agreeableness often look for ways to achieve the team's goals, even if they are in conflict with their own goals [15]. In teams with high agreeableness, members try to engage in positive interpersonal processes, maintain social harmony, and reduce within-group competition [32]. By contrast, teams low in agreeableness tend to be argumentative, inflexible, uncooperative, intolerant, and disagreeable, thus displaying lower teamwork [32]. According to McGrath [33], when team members' opinions converge, they experience increased cohesion. Hence, when teams engage in a feedback review process, high agreeableness might help them to develop team cohesion through consensus and agreement.

Therefore, we propose a moderated mediation model where team personality traits (openness to experience and agreeableness) moderate the indirect effect of a team feedback and guided reflection intervention on TL through team cohesion, using a moderated mediational model, in VTs. Figure 1 presents the research model. Consequently, we propose the following two hypotheses:

Hypothesis 2: The indirect effect of team feedback with reflection on team learning via team cohesion will be moderated by openness to experience.

Hypothesis 3: The indirect effect of team feedback with reflection on team learning via team cohesion will be moderated by agreeableness. 


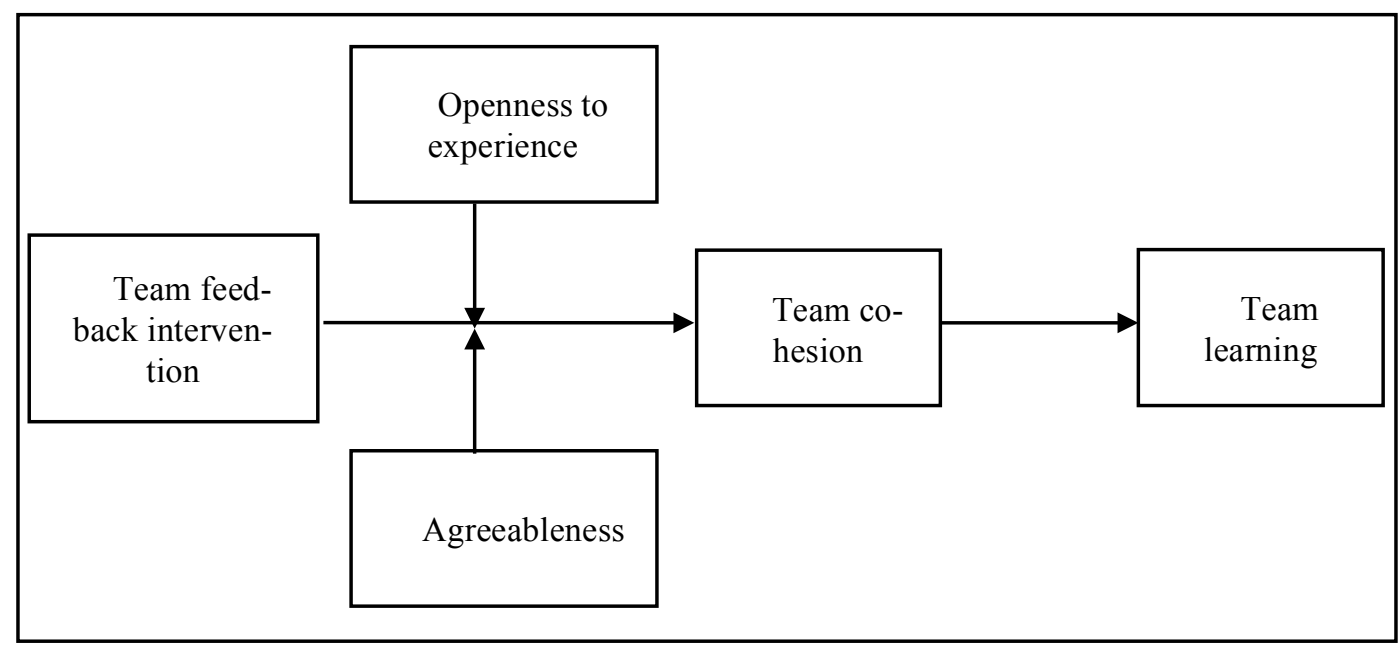

Fig. 1. Research model.

\section{$2 \quad$ Method}

\subsection{Sample}

The sample was composed of 212 students enrolled in an Organizational Psychology course at a Spanish University. Gender distribution was 169 females and 43 males, with an average age of 23.91 years $(\mathrm{SD}=4.38)$. Participants were randomly assigned to teams of four members, taking into account the gender balance and maintaining the existing proportion of men to women among the population in the School of Psychology (there are three females and one male on each team). This process resulted in 54 participating teams. Participation in this experiment was voluntary, and it was an alternative way to complete the practical classes in the course.

\subsection{Procedure}

A laboratory experimental study was designed to test the hypotheses of this study. Teams were randomly assigned to either the experimental (twenty-eight teams) or control (twenty-six teams) condition. The two conditions were equal, except that the experimental teams received feedback. Each team attended the laboratory for three weeks, carrying out one work session each week. Participants attended an informative meeting where they signed a contract declaring their commitment to participating in the experiment, which included a norm stating that the participants were not allowed to meet their teammates outside the laboratory during the experiment. This was controlled by checking the chat logs created during the work sessions. 
The tasks used were decision-making tasks and correspond to quadrant 2 of Argote and McGrath's [34] circumflex model, where the objective is to select a response proposed by the team, and the level of interdependence between team members is high. These tasks are suitable for delivering outcome and process feedback. The team feedback manipulation is described below.

During sessions 1 and 2, teams performed two decision-making tasks with a correct answer provided by experts (intellective tasks), "Lost at sea" [35] and "Wildfire" [36], making it possible to deliver team performance feedback.

During session 3, teams performed a decision task simulating a business environment, increasing the possibility of generalizing the results to real project teams. Teams had to select and arrange three human resources services from a pool of 12 possible services distributed among team members. After each session, participants completed an electronic questionnaire with the measures used in this study.

All teams worked in a virtual setting using synchronous CMC via Microsoft Groove 2007. In fact, each participant worked in a separate room at a workstation, and they were not informed of the team composition. This program features several tools (chat, whiteboard, notepad, shared workspace) that allow teams to work and share using the computer. During the informative meeting, all participants were briefly instructed in the use of this specific program for $15 \mathrm{~min}$.

\subsection{Team feedback and guided reflection intervention}

A team feedback and guided reflection intervention was carried out in session 1 and session 2. It was based on the delivery of outcome and process feedback and a subsequent reflection period about it.

Teams received outcome feedback about the quality of the decision reached by each team and its members. The researcher acted as an instructor, guiding the team in understanding the feedback. The main requirements to solve these tasks consist of analyzing the situation, combining the individual contributions adequately, and developing an effective communication process.

In this vein, process feedback was based on individual and group perceptions of the interaction process developed while completing the tasks. These perceptions were collected through a checklist proposed in the studies by Warkentin and Beranek [37] and Beranek and Martz [38]. Team members rated several items on a 5-point scale. This information was summarized on a graph representing the levels of these perceptions. The core group processes included were: planning (e.g., "At the beginning of the team interaction, we defined the goals"), coordination (e.g., "We established a sequence to take turns speaking"), written communication strategies (e.g., "Team members used short, direct sentences to communicate'), information sharing management (e.g., "Team members shared their information and knowledge"), and socio-emotional processes (e.g., "Team members relied on other team members to solve any problems arising during the interaction"). The instructor acted as a coach by helping the team to analyze its results. 
Next, the instructor asked the team to discuss their strengths and weaknesses to design strategies to improve their efficacy in future sessions. Fig. 2 shows the procedure for experimental and control teams.
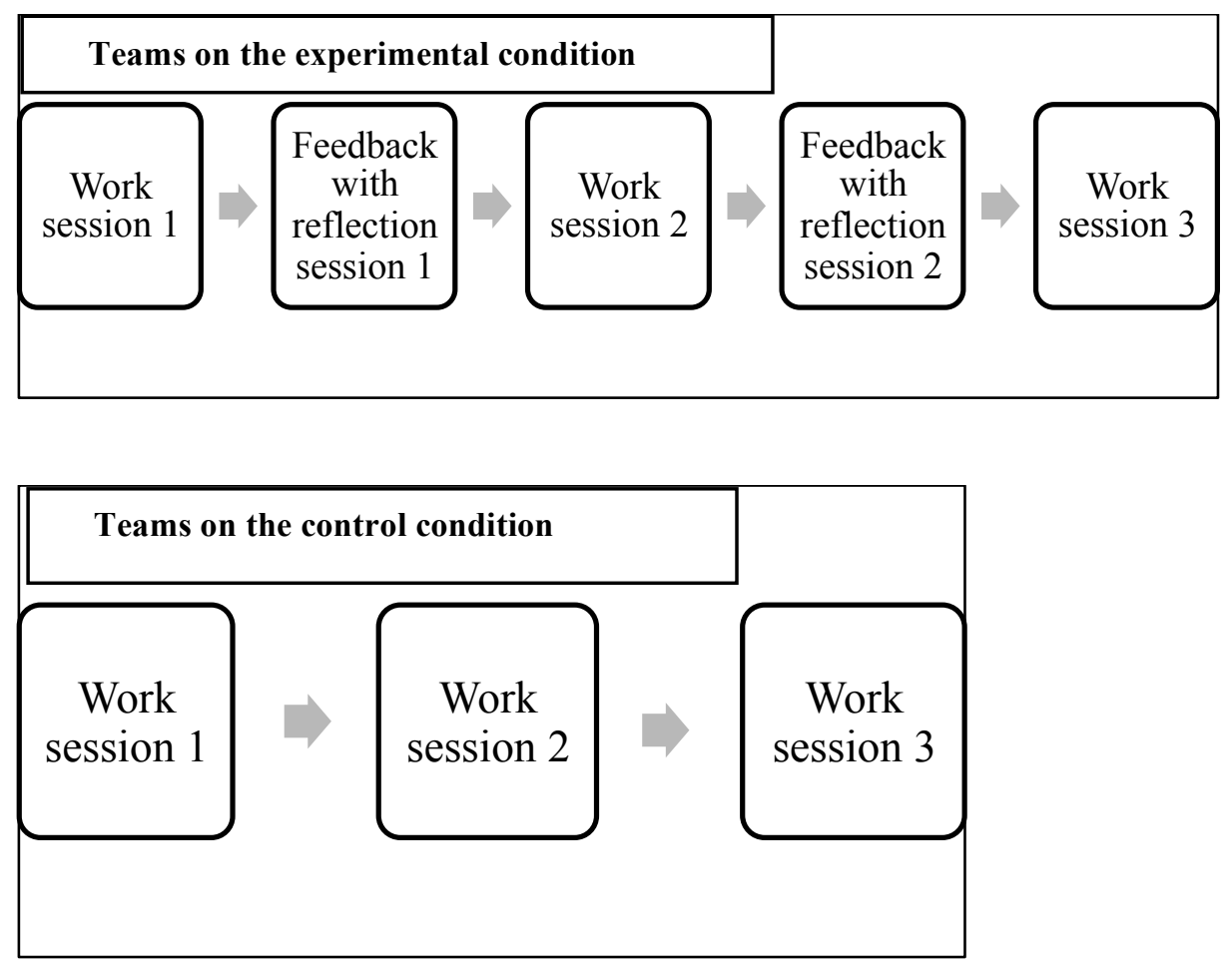

Fig. 2. Procedure for experimental and control teams.

\subsection{Measures}

Team personality traits were measured with items from Caprara, Barbaranelli and Borgogni [39], using a 5-point Likert scale from "Very low" (1) to "Very High" (5). Data were aggregated at the team level for each trait by calculating the mean for each team. Personality traits are not a shared property of the team, and team members' scores are not expected to coalesce; therefore, the calculation of aggregation indices and interrater agreement statistics is not necessary [28].

Openness to experience: This variable was measured with 3 items. An example of an openness to experience item was "I am a person who always looks for new experiences". Cronbach's alpha for the aggregated scores was .70.

Agreeableness: This variable was measured using 5 items. An example of an agreeableness item was "I am convinced that I can obtain better results by cooperating with others rather than competing". Cronbach's alpha for the aggregated scores was .71 . 
Team cohesion: This variable was measured by 4 items taken from Karn et al. [40], after work session 2, once the team had received feedback. An example of an item was "To what extent are individuals in your project team helpful to you in getting your work done?". The items were measured on a 5-point Likert scale from "Not at all" (1) to "A lot"' (5). Aggregation at the team level was justified, as we obtained the following results: the mean of the $A D_{M_{(j)}}$ was $.43(\mathrm{SD}=.24)$; ICC (1) was .22; and the ANOVA was statistically significant $(\mathrm{F}(53,158)=2.10 ; \mathrm{p}<.01)$. Furthermore, Cronbach's alpha for the aggregated scores was .83 .

Team Learning: This variable was measured by five items taken from Edmondson [4], after working session 1 and session 3. An example of an item was: "This team regularly takes time to figure out ways to improve its work performance". The items were measured on a 5-point Likert scale from "I strongly disagree" (1) to "I strongly agree" (5). Data were aggregated at the team level. For session 1, aggregation was justified, as we obtained the following results: the mean of the $A D_{M_{(j)}}$ was .59 ( $\left.\mathrm{SD}=.30\right)$; ICC (1) was .15 ; and the ANOVA was statistically significant $(\mathrm{F}(53,158)=1.72 ; \mathrm{p}<.01)$. Cronbach's alpha for the aggregated scores was .83. For session 3, aggregation was justified, as we obtained the following results: the mean of the $A D_{M_{(j)}}$ was $.51(\mathrm{SD}=.25)$; ICC (1) was .21 ; and the ANOVA was statistically significant $(\mathrm{F}(53,158)=2.06 ; \mathrm{p}<.01)$. Furthermore, Cronbach's alpha for the aggregated scores was .86 .

\section{$3 \quad$ Results}

\subsection{Preliminary analyses}

Descriptive statistics and correlations were calculated for all the variables in this study and shown in table 1 .

Table 1. Descriptive statistics and correlations.

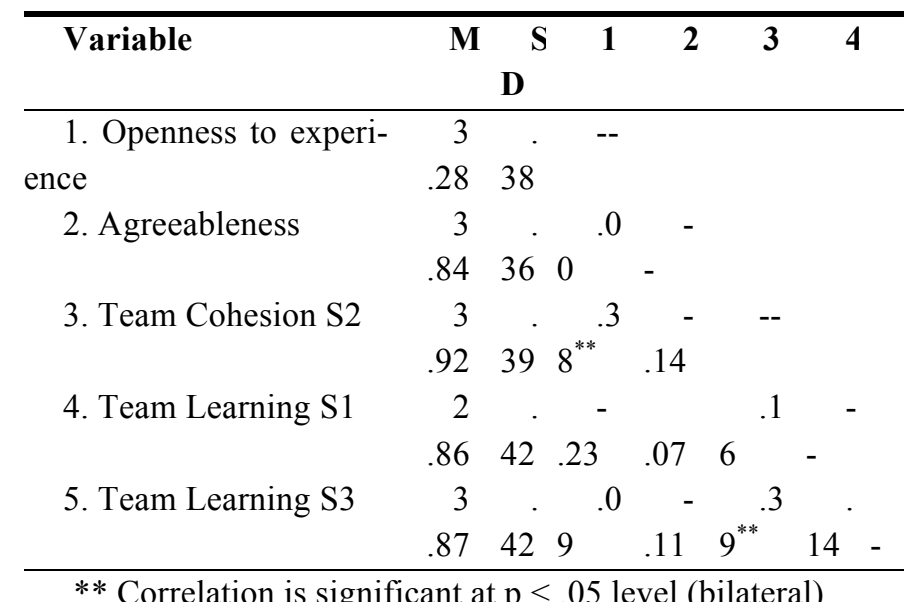

** Correlation is significant at $\mathrm{p}<.05$ level (bilateral) 
The variables of this study showed moderate inter-correlations, and we conducted two confirmatory factor analyses to ascertain discriminant validity. Specifically, we compared the fit of a four-factor model (the items load in four correlated factors) to the fit of an alternative one-factor model (all the items load in one factor). We performed these analyses using MPLUS 6 [41] with the DIFFTEST option (279.61, d.f. $=$ $6, \mathrm{p}<.01)$; fit indices are shown in table 2 .

Table 2. Confirmatory factor analysis fit indices for one-factor and four-factor models.

\begin{tabular}{|c|c|c|c|c|c|c|c|}
\hline Model & $\chi^{2}$ & .f. ${ }^{d}$ & $\mathbf{p}$ & $\begin{array}{l}\chi^{2} / \\
\text { d.f. }\end{array}$ & $\begin{array}{l}\text { RMS } \\
\text { EA }\end{array}$ & ${ }_{L I}^{T}$ & ${ }_{\text {FI }}$ C \\
\hline Four factors & 134 & 9 & & 1. & 0.04 & & . \\
\hline One factor & $\begin{array}{c}.34 \\
841 \\
.97\end{array}$ & $\begin{array}{l}8 \\
04\end{array}$ & $01^{0}$ & ${ }_{10}^{37} 8$ & 0.18 & ${ }_{48}$. & ${ }_{55^{\circ}}^{98}$ \\
\hline
\end{tabular}

\subsection{Regression analyses}

The regression analyses were conducted with the PROCESS macro [42], which allows the use of bootstrapping when testing for mediation and conditional effects [43]. Aggregated scores of TL for session 1 are introduced as statistical control in further analyses. Moreover, as we used the same measurement method (e.g., questionnaire) to assess the mediator and dependent variables, it is likely that they share systematic covariation [44] . However, we tested the effect of the mediator on the dependent variable at different points in time, rather than concurrently, which minimizes the effect of common method bias. Hence, we tested the effect of team cohesion measured in session 2 on TL measured in session 3.

First, bootstrap analysis showed that the indirect effect of team feedback on TL via team cohesion was significantly different from zero (estimate of ab product term $=.08$; boot $\mathrm{SE}=.05 ; 95 \%$ confidence interval $=.01$ to .20 ). However, the direct effect of team feedback on TL was not significantly different from zero (estimate of $\mathrm{c}^{\prime}=.13$; boot $\mathrm{SE}=.11 ; 95 \%$ confidence interval $=-.10$ to .34 ). Thus, hypothesis 1 is supported.

Second, bootstrap analysis showed that openness to experience moderates the indirect effect of team feedback on TL via team cohesion, and the index of moderated mediation [42] is significantly different from zero, with an estimate of -.15 (boot $\mathrm{SE}=$ $.10 ; 95 \%$ confidence interval $=-.41$ to -.02 ). Specifically, at low levels of openness to experience, the product term was significantly different from zero (estimate of ab product term $=.13$; boot $\mathrm{SE}=.06 ; 95 \%$ confidence interval $=.03$ to .30 ), whereas at high levels of openness to experience, it was not significantly different from zero (estimate of ab product term $=.01$; boot $\mathrm{SE}=.05 ; 95 \%$ confidence interval $=-.08$ to .11). Hence, hypothesis 2 is supported. Figure 3 shows the statistical diagram for hypothesis 2 . 
Third, bootstrap analysis showed that agreeableness does not moderate the indirect effect of team feedback on TL through team cohesion. The index of moderated mediation is not significantly different from zero, with an estimate of .12 (boot $\mathrm{SE}=.14 ; 95 \%$ confidence interval $=-.01$ to .48 ). Therefore, hypothesis 3 is not supported. Figure 4 shows the statistical diagram for hypothesis 3 .

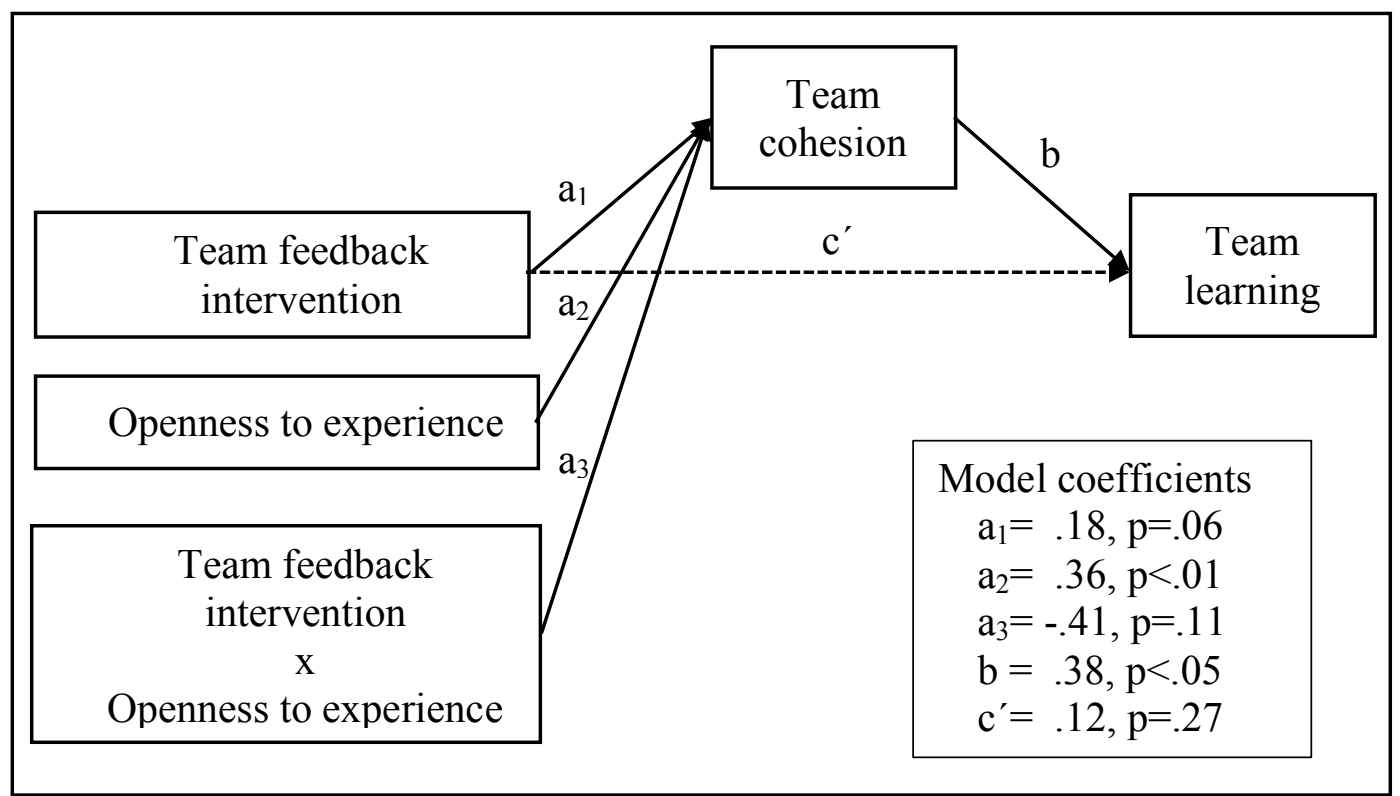

Fig 3. Statistical diagram for hypothesis 2 .

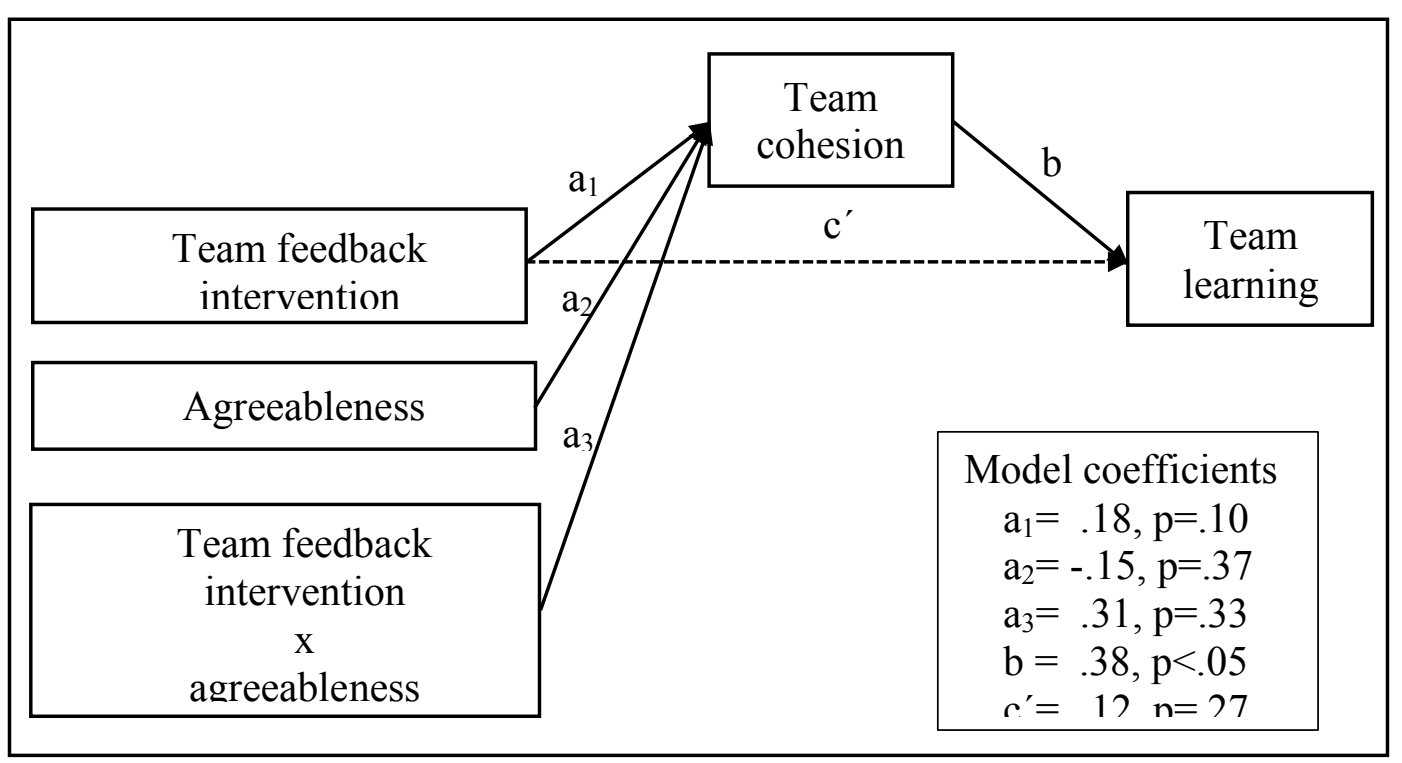

Fig. 4. Statistical diagram for hypothesis 3. 


\section{Discussion}

The aim of this paper was to study the indirect effects of a team feedback with guided reflection intervention on TL through team cohesion, as well as the moderator role of team personality (openness to experience and agreeableness), in VTs.

We found that the team feedback intervention had a significant indirect effect on team learning via team cohesion in VTs. This result supports Hypothesis 1. Our findings highlight the importance of emergent states to develop TL in VTs. The proposed training intervention based on feedback and guided reflection encourages teams to discuss, share information, and set goals collaboratively. It becomes a team effort that requires the VT's members to jointly focus their attention on how to improve their teamwork and achieve their goals, favoring the emergence of team cohesion. Thus, team members develop feelings of closeness with other teammates and strengthen their commitment to the team's objectives [5]. These findings increase the understanding of how an intervention based on team feedback and guided reflection might improve TL in VTs. These findings support the positive effects of team training interventions in VTs [1]. Moreover, the effect of the intervention is mediated by team cohesion.

Past literature highlighted the need to study the effects that team composition might have on the effects of interventions [24]. Our results suggest that the mediated effect of team feedback and guided reflection on TL via team cohesion is negatively moderated by openness to experience. Thus, hypothesis 2 was supported. Specifically, teams with low openness to experience benefit more from the intervention than teams with a high level of openness. Less open-minded teams might have difficulties in considering new perspectives to solve problems and learn from others. Thus, helping them to reflect and discuss about the feedback might foster the emergence of cohesion and facilitate the members' engagement in team learning behaviors.

However, we did not find support for the moderating effect of agreeableness on the mediated relationship studied. Hence, hypothesis 3 was not supported. One possible reason for this result could be the homogeneity of the sample. All the participants were university students, and the majority were women. It would be interesting to test this moderation in a different setting with teams that differ in experience and have greater cultural diversity, where agreeableness might play a more significant role. Previous research found that high levels of agreeableness might prevent teams from evaluating different opinions or new information, thus hindering team learning, but improving cohesion [5].

In conclusion, this study highlights the importance of considering aspects related to the team composition when devising intervention strategies for VTs, and it provides empirical support for an interactionist model between personality and emergent states such as cohesion.

This study presents some limitations and implications for future research. First, we studied newly formed VTs in a laboratory setting, which limits the generalizability and external validity of the results to real organizational settings. In organizational contexts, VTs vary in their duration and purpose; therefore, it is also necessary to study the effectiveness of team feedback in already existing VTs [45]. Second, the 
present study does not analyze the effectiveness of this intervention on a long-term basis. Further research should address this by contemplating these long-term effects in real organizational environments. Finally, in this study all data were collected through self-report surveys, which raises the issue of common method variance as a potential problem [44]. However, several statistical analyses were successfully conducted to control this issue.

From a practical point of view, this study provides managers with some guidance about how to train VTs to improve TL. Encouraging the team to review its results and providing guidelines for processing feedback seem to be useful strategies for promoting team learning. The proposed intervention enhances team learning by fostering members' commitment to the team's goals and the creation of positive relationships. Furthermore, our results suggest that managers should consider that VTs with low openness to experience might benefit more from the proposed training intervention. This study is especially relevant for newly formed VTs with unacquainted members.

\section{References}

1. Gilson, L.L., Maynard, M.T., Jones Young, N.C., Vartiainen, M., Hakonen, M.: Virtual Teams Research: 10 Years, 10 Themes, and 10 Opportunities. J. Manag. 41, 1313-1337 (2015).

2. Boon, A., Raes, E., Kyndt, E., Dochy, F.: Team learning beliefs and behaviours in response teams. Eur. J. Train. Dev. 37, 357-379 (2013).

3. Van den Bossche, P., Gijselaers, W.H., Segers, M., Kirschner, P.A.: Social and Cognitive Factors Driving Teamwork in Collaborative Learning Environments: Team Learning Beliefs and Behaviors. Small Group Res. 37, 490-521 (2006).

4. Edmondson, A.C.: Psychological Safety and Learning Behavior in Work Teams. Adm. Sci. Q. 44, 350 (1999).

5. Bell, B.S., Kozlowski, S.W.J., Blawath, S.: Team learning: A theoretical integration and review. (2012).

6. Ortega, A., Sánchez-Manzanares, M., Gil, F., Rico, R.: Team Learning and Effectiveness in Virtual Project Teams: The Role of Beliefs about Interpersonal Context. Span. J. Psychol. 13, 267-276 (2010).

7. Wong, S.-S.: Distal and Local Group Learning: Performance Trade-offs and Tensions. Organ. Sci. 15, 645-656 (2004).

8. Tannenbaum, S.I., Mathieu, J.E., Salas, E., Cohen, D.: Teams are changing: Are research and practice evolving fast enough? Ind. Organ. Psychol. 5, 2-24 (2012).

9. Armstrong, D.J., Cole, P.: Managing distances and differences in geographically distributed work groups. In: Hinds, P. and Kiesler, S. (eds.) New ways of working across distance using technology. pp. 167-189. MIT Press, Cambridge, MA (2002).

10. Baltes, B.B., Dickson, M.W., Sherman, M.P., Bauer, C.C., LaGanke, J.S.: ComputerMediated Communication and Group Decision Making: A Meta-Analysis. Organ. Behav. Hum. Decis. Process. 87, 156-179 (2002).

11. Curşeu, P.L., Schalk, R., Wessel, I.: How do virtual teams process information? A literature review and implications for management. J. Manag. Psychol. 23, 628-652 (2008). 
12. Driskell, J.E., Radtke, P.H., Salas, E.: Virtual Teams: Effects of Technological Mediation on Team Performance. Group Dyn. Theory Res. Pract. 7, 297-323 (2003).

13. Lacerenza, C.N., Zajac, S., Savage, N., Salas, E.: Team Training for Global Virtual Teams: Strategies for Success. In: Wildman, J.L. and Griffith, R.L. (eds.) Leading Global Teams. pp. 91-121. Springer New York, New York, NY (2015).

14. LePine, J.A.: Team adaptation and postchange performance: Effects of team composition in terms of members' cognitive ability and personality. J. Appl. Psychol. 88, 27-39 (2003).

15. van Vianen, A.E.M., De Dreu, C.K.W.: Personality in teams: Its relationship to social cohesion, task cohesion, and team performance. Eur. J. Work Organ. Psychol. 10, 97-120 (2001).

16. Tekleab, A.G., Quigley, N.R., Tesluk, P.E.: A Longitudinal Study of Team Conflict, Conflict Management, Cohesion, and Team Effectiveness. Group Organ. Manag. 34, 170-205 (2009).

17. Burke, K., Aytes, K., Chidambaram, L.: Media effects on the development of cohesion and process satisfaction in computer-supported workgroups - An analysis of results from two longitudinal studies. Inf. Technol. People. 14, 122-141 (2001).

18. Dennis, A.R., Garfield, M.J.: The Adoption and Use of GSS in Project Teams: Toward More Participative Processes and Outcomes. MIS Q. 27, 289-323 (2003).

19. Gabelica, C., Van den Bossche, P., Segers, M., Gijselaers, W.: Feedback, a powerful lever in teams: A review. Educ. Res. Rev. 7, 123-144 (2012).

20. Gabelica, C., Van den Bossche, P., Segers, M., Gijselaers, W.: Dynamics of team reflexivity after feedback. Frontline Learn. Res. 2, 64-91 (2014).

21. Villado, A.J., Arthur, W.: The comparative effect of subjective and objective after-action reviews on team performance on a complex task. J. Appl. Psychol. 98, 514-528 (2013).

22. Schippers, M.C., Homan, A.C., van Knippenberg, D.: To reflect or not to reflect: Prior team performance as a boundary condition of the effects of reflexivity on learning and final team performance: boundary conditions of team reflexivity. J. Organ. Behav. 34, 6-23 (2013).

23. Konradt, U., Otte, K.-P., Schippers, M.C., Steenfatt, C.: Reflexivity in Teams: A Review and New Perspectives. J. Psychol. 150, 153-174 (2016).

24. Salas, E., DiazGranados, D., Klein, C., Burke, C.S., Stagl, K.C., Goodwin, G.F., Halpin, S.M.: Does Team Training Improve Team Performance? A Meta-Analysis. Hum. Factors. 50, 903-933 (2008).

25. Bell, B.S., Tannenbaum, S.I., Ford, J.K., Noe, R.A., Kraiger, K.: 100 years of training and development research: What we know and where we should go. J. Appl. Psychol. 102, 305-323 (2017).

26. DeRue, D.S., Nahrgang, J.D., Hollenbeck, J.R., Workman, K.: A quasi-experimental study of after-event reviews and leadership development. J. Appl. Psychol. 97, 997-1015 (2012).

27. Bradley, B.H., Klotz, A.C., Postlethwaite, B.E., Brown, K.G.: Ready to rumble: How team personality composition and task conflict interact to improve performance. J. Appl. Psychol. 98, 385-392 (2013).

28. MacDonnell, R., O’Neill, T., Kline, T., Hambley, L.: Bringing group-level personality to the electronic realm: A comparison of face-to-face and virtual contexts. Psychol.-Manag. J. 12, 1-24 (2009).

29. Ellis, A.P.J., Hollenbeck, J.R., Ilgen, D.R., Porter, C.O.L.H., West, B.J., Moon, H.: Team learning: Collectively connecting the dots. J. Appl. Psychol. 88, 821-835 (2003).

30. Costa, P.T., McCrae, R.R.: Normal personality assessment in clinical practice: The NEO Personality Inventory. Psychol. Assess. 4, 5-13 (1992). 
31. McCrae, R.R.: Creativity, divergent thinking, and openness to experience. J. Pers. Soc. Psychol. 52, 1258-1265 (1987).

32. Barrick, M.R., Mount, M.K., Judge, T.A.: Personality and Performance at the Beginning of the New Millennium: What Do We Know and Where Do We Go Next? Int. J. Sel. Assess. 9, 9-30 (2001).

33. McGrath, J.E.: Groups: Interaction and performance. Prentice-Hall Englewood Cliffs, NJ (1984).

34. Argote, L., McGrath, J.E.: Group processes in organizations: Continuity and change. Int. Rev. Ind. Organ. Psychol. 8, 333-389 (1993).

35. Gordon, J. ed: Pfeiffer's classic activities for building better teams: the most enduring effective, and valuable training activities for developing teams. Jossey-Bass/Pfeiffer, San Francisco, Calif (2004).

36. Human Synergistics International: Bushfire Survival Situation: Leader's Guide. Human Synergistics International (2005).

37. Warkentin, M., Beranek, P.M.: Training to improve virtual team communication. Inf. Syst. J. 9, 271-289 (1999).

38. Beranek, P.M., Martz, B.: Making virtual teams more effective: improving relational links. Team Perform. Manag. Int. J. 11, 200-213 (2005).

39. Caprara, G.V., Barbaranelli, C., Borgogni, L.: BFQ Cuestionario "Big Five," (1998).

40. Karn, J.S., Syed-Abdullah, S., Cowling, A.J., Holcombe, M.: A study into the effects of personality type and methodology on cohesion in software engineering teams. Behav. Inf. Technol. 26, 99-111 (2007).

41. Muthén, L.K., Muthén, B.O.: Mplus. Stat. Anal. Latent Var. User's Guide. 3, (1998).

42. Hayes, A.F.: Introduction to mediation, moderation, and conditional process analysis: a regression-based approach. The Guilford Press, New York (2013).

43. Hayes, A.F.: Beyond Baron and Kenny: Statistical Mediation Analysis in the New Millennium. Commun. Monogr. 76, 408-420 (2009).

44. Podsakoff, P.M., MacKenzie, S.B., Lee, J.-Y., Podsakoff, N.P.: Common method biases in behavioral research: A critical review of the literature and recommended remedies. J. Appl. Psychol. 88, 879-903 (2003).

45. Geister, S., Konradt, U., Hertel, G.: Effects of Process Feedback on Motivation, Satisfaction, and Performance in Virtual Teams. Small Group Res. 37, 459-489 (2006). 